\title{
Contamination of Rumen Samples During Washing
}

\section{JOHN PICKARD}

This note draws attention to contamination of rumen samples by unfiltered rural water used to wash the samples in the field.

Botanical analysis of rumen and stomach contents is a standard research tool for investigating food preferences of range animals; Chippendale (1962) discusses some of the assumptions and limitations of the technique.

While investigating the diet of feral goats on Lord Howe Island $\left(31^{\circ}\right.$ $32^{\prime} \mathrm{S} 159^{\circ} 05^{\prime} \mathrm{E}$ ), I found that some of the rumen contents had been contaminated. The contaminant material was brightly coloured flowers of Acacia saligna, which is localized on the island to a few cultivated plants near habitation.

Author is senior plant ecologist, Royal Botanic Gardens, Sydney, N.S.W., Australia, 2000.

Field work was financed by the Lord Howe Island Board of New South Wales Department of Agriculture.
The Acacias are planted about $100 \mathrm{~m}$ upwind from open steel tanks used to maintain a pressure head on non-drinking water, which is pumped from covered wells. The small flowers (about $3 \mathrm{~mm} \mathrm{dia.)}$ most likely were blown from the shrubs into the tank by the almost incessant on-shore winds. The goats were shot nearly $2 \mathrm{~km}$ away and had no access to the plants and the Acacia flowers could only have contaminated the samples via the water supply.

The rumen contents were removed by hand into clean polythene bags and washed on a $1.5-\mathrm{mm}$ sieve. They were then spread in thin layers on clean newspaper and dried in a plant press.

In many investigations, contamination of this type will be undetectable. Alternatives to field washing with unfiltered rural water are to use ad hoc filters such as cloth or a preservative such as formalin.

\section{Literature Cited}

Chippendale, G. M. 1962. Methods of investigation of fodder preferences under range conditions. Advancing Frontiers of Plant Sci. 1:23-30. 